\title{
A Flight Simulator-Based Active Learning Environment
}

\author{
Chadia Affane Aji, M. Javed Khan \\ Tuskegee University, Tuskegee, Alabama, USA \\ Email: caji@tuskegee.edu,mjkhan@tuskegee.edu
}

How to cite this paper: Aji, C.A. and Khan, M.J. (2019) A Flight Simulator-Based Active Learning Environment. Open Journal of Social Sciences, 7, 192-203. https://doi.org/10.4236/jss.2019.73016

Received: December 5, 2018 Accepted: March 10, 2019

Published: March 13, 2019

\begin{abstract}
The U.S. K-12 education continues to face two major challenges, the poor performance of students in math and science in comparison to other industrialized nations of the world and paucity of professional development on integrating technology in teaching for rural school teachers. While there certainly are structural reasons for this situation, pedagogical elements contribute as well. Motivation and engagement in the classroom lead to deeper learning and academic success. The learning environment therefore should engage students affectively, behaviorally and cognitively. However, the design and implementation of a learning environment to engage and motivate students is a major aspect of the pedagogical challenge. Appropriate use of technology can support the design of such a learning environment. This paper provides details of an innovative technology-based learning environment to teach certain math and physics concepts to middle school students. Learning modules using an active-learning approach through the incorporation of flight simulation software were developed. The pedagogical approach was modeled in a teacher professional development workshop. An increase was observed in teaching efficacy and outcomes expectancy of the teachers who participated in the professional development. Post workshop data indicated the teachers' acceptance of the effectiveness of the pedagogy and self-efficacy in using the approach.
\end{abstract}

\section{Keywords}

STEM, Active Learning, K-12, Flight Simulation, Teacher Professional Development

\section{Introduction}

Significant improvements in technology and its affordability is forcing changes 
in the traditional teaching and learning methodologies across the spectrum of education. Innovative approaches for active-learning are being developed in the US to mitigate the challenges being faced by the K-12 education system in the US. The impact of these challenges is visible in the performance of US students on math, science and reading as measured by the Program for International Student Assessment (PISA) which is conducted by the Organization for Economic Cooperation and Development (OECD). According the 2015 PISA results [1], the average performance of US students ranked $19^{\text {th }}$ in science and a dismal $30^{\text {th }}$ in math among the 35 members of the OECD.

There are several structural aspects that contribute to the non-competitive performance of US students. For example, a strong correlation has been observed between economic status and academic performance of K-12 students. It has been reported by the National Education Association [2] that $80 \%$ of students who are eligible for free or reduced lunch programs under the National School Lunch Program (NSLP) are below basic proficiency in $8^{\text {th }}$ grade math as compared to only $14 \%$ of students who are not eligible for NSLP. In addition to economic status, access stratification has been observed along ethnic lines. In 2015-16, the $8^{\text {th }}$ grade enrollment in schools that offered Algebra-I consisted of $49 \%$ White students and $17 \%$ African-American students [3]. However, of these $8^{\text {th }}$ grade students only $11 \%$ African-American students were enrolled in Algebra-I in comparison to $58 \%$ of the White students.

The other major challenge is the insufficiency of professional development opportunities for teachers in rural school districts, especially in using technology effectively to enhance the learning experiences of students in comparison to their urban peers. The results of a survey of 4000 middle school students [4] indicated that students generally thought their teachers were "out of touch" with technology and did not fully recognize its importance in their lives. Fewer opportunities for professional development in technology-supported learning has a major impact on student learning since $28 \%$ of the public elementary and secondary schools serves rural student populations which comprise $19 \%$ of the total $\mathrm{K}-12$ students in the US [5].

In view of the challenges summarized above, a one-week long professional development summer workshop was designed and conducted to train math and science middle school teachers from rural, economically depressed school districts in incorporating an innovative technology supported learning environment in their classrooms. This learning environment was designed to motivate and cognitively, behaviorally, and emotionally engage middle school students. The data gathered during the research was analyzed to answer the following questions:

1) How did the professional development summer workshop impact the math and science teaching self-efficacy of the participant teachers?

2) Was the professional development summer workshop design perceived to be effective by the participant teachers?

3) What were the participant teachers' perceptions on the effectiveness of the 
learning environment with the integration of the innovative approach?

\section{Method and Materials}

The study was a quasi-experimental within subject design. Middle school teachers applied for the professional development workshop and were provided a stipend for their participation.

\subsection{Participants}

The participants were middle school math $(\mathrm{N}=16)$ and science $(\mathrm{N}=18)$ teachers from rural school districts and were from underrepresented groups in science, technology, engineering and mathematics (STEM).

\subsection{Technology Supported Learning Environment}

The active learning environment has been designed around the flight simulation hardware/software. The main reason of choosing this technology to develop the active learning activities is the excitement of flying an airplane. The other reasons are that the flight simulation software which has a reasonable flight physics model and the associated hardware are inexpensive and within easy reach. The learning environment has two versions, a desk-top version and a version with three large-screen out of the window views (Figure 1). The desk-top version uses one desktop PC and includes an USB-connected integrated throttle-joystick. The large-screen version is run by four desktop PCs. Each out of the window view uses an LCD projector and is run by one PC. The three PCs running the out of windows views are slaved to a fourth PC which is the main control computer. The instrument panel display is run by the main control computer. The flight simulator software is the Microsoft Flight Simulator X (FSX). A shareware flight data recorder (FDR) is used to record flight data and the FSUPIC [6] shareware is used for the communication between the FSX and FDR. The large-screen version uses an additional shareware [7] to synchronize the three large-screen out of the window views and the cockpit display.

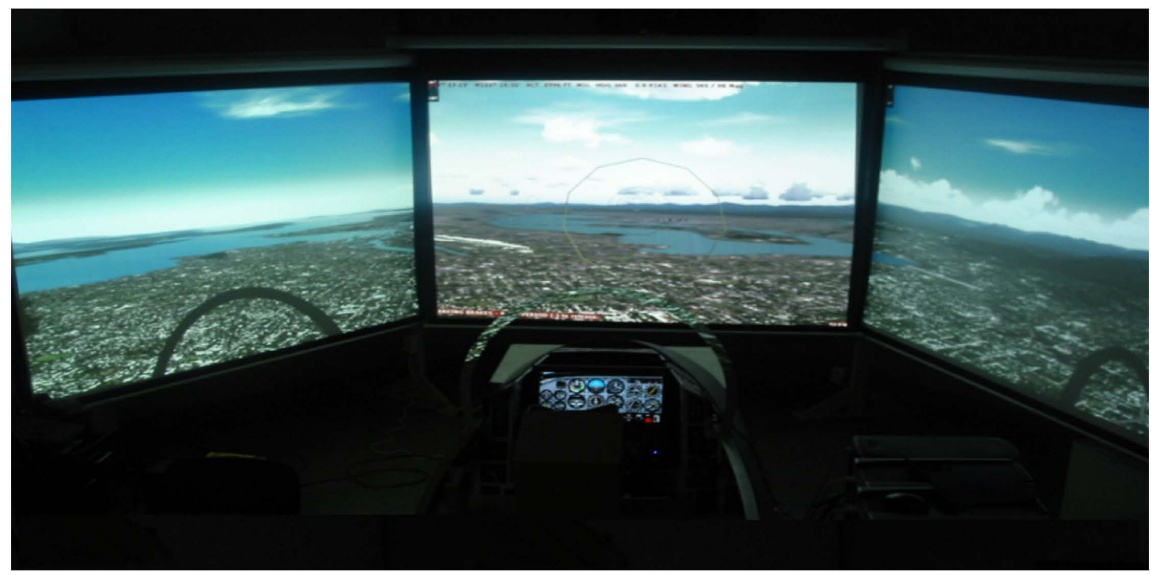

Figure 1. Large screen flight simulator. 
A number of lesson plans have been developed to teach selected math and science concepts that were suggested by the middle school teachers considered by them as challenging topics for their students. Designing the lessons based on the recommendation of the teachers is expected to result in buy-in from the teachers and hence increase their motivation to implement the pedagogical approach in their classrooms. Additionally, since the lessons are aligned with standards, in this case the Alabama Course of Study, the teachers will not consider the content to be something "extra" that they have to teach. Each lesson has a flight simulator mission associated with it. Flying a mission in the simulator is not a trivial task, especially if specific flight parameters are to be maintained, a requirement to collect useful data to be utilized for learning the math or science concept. The software was therefore modified so that aircraft is appropriately constrained. For example, executing a level turn requires a fair amount of skill. Thus, the software for the flight lesson was designed to constrain the aircraft such that the altitude of the aircraft does not change as the pilot executes a level turn. The pilot has only the bank angle to control providing some challenge yet allowing collection of useful data. The student is provided instructions displayed on the monitor while flying a mission. The flight data is automatically recorded and saved in real time to a text file. The saved data from the text file can then be exported to Excel. The needed data can then be extracted to be analyzed for understanding the concept.

The lesson plans developed so far are available on www.flyhightu.weebly.com. Additional lessons are in the process of being developed. Each module has the four components:

1) Concept basics (Workshop module)

2) Paper and pencil activities

3) Flight simulator activities

4) Lesson plan sample

\subsection{Professional Development Summer Workshop Design}

The professional development was provided as a one-week workshop during the summer of 2017 and 2018. Training on using the needed technology (hardware/software) was a component of the professional development. The workshop design was based on best practices of effective professional development for teachers [8] and included the following:

- Content focus-The workshop was focused on using the flight simulator-based activities to teach specific math and science concepts.

- Active learning-The participant teachers used the flight simulator to collect, analyze and interpret the data following the process that they would use in class with their students.

- Collaboration-The teachers were provided an opportunity to work in groups. They discussed and developed their own lesson plans using the flight simulator data. 
- Models of effective practice-The workshop providers/facilitators modeled the effective use of the teaching environment by providing exemplar lessons.

- Coaching and expert support-The workshop facilitators provided coaching and expert support to the teachers on developing their own lesson plans incorporating flight simulator activities.

- Feedback and reflection-The teachers were provided the opportunity to present their learning modules, receive feedback from their peers and the workshop facilitators to reflect on their understanding of the use of the learning environment.

The professional development summer workshop had the following components:

- Introduction to the pedagogical approach and the expected learning outcomes of the professional development

- Basics of the physics of flight which included explanation of the forces on an aircraft, generation of lift and drag and propulsion systems

- Aircraft flight and cockpit controls, and basic flight instruments

- Flying a mission, recording data

- Introduction to Excel (review of basics including graphing)

- Data analysis (importing data from FDR text file to Excel, extracting and plotting relevant data in Excel)

- Introduction and teaching of one math and one physics lesson module

- Development, presentation and discussion of lesson modules by teacher teams

\subsection{Typical Active-Learning Module}

The concepts of slope, its relation with the rate of change of quantities such as distance and speed are included in the learning modules that has been developed (Module 3, www.flyhighjtu.weebly.com). As previously pointed out the module has a "Basics" component which explains the various techniques of finding the slope of a straight line. The students then practice solving some problems (paper pencil activity). The "Flight Simulator Activity" is a straight and level constant speed, accelerating and decelerating mission. The aircraft is constrained to constant altitude and heading and the pilot has only the throttle control to accelerate and decelerate the aircraft. During the flight, the student is provided visual instruction on the display (Figure 2(a)) as to when to start recording the data, increasing and reducing throttle and stopping collection of data. At the end of the flight, the flight data which is stored in a text file is imported to an Excel sheet by the student. The relevant data which in this case are time and speed is extracted to another Excel sheet and is plotted (Figure 2(b)). The student then answers questions based on the flight data regarding slopes, acceleration, deceleration etc.

\subsection{Assessment Instruments}

The self-efficacy of the participant teachers of the Summer Professional 


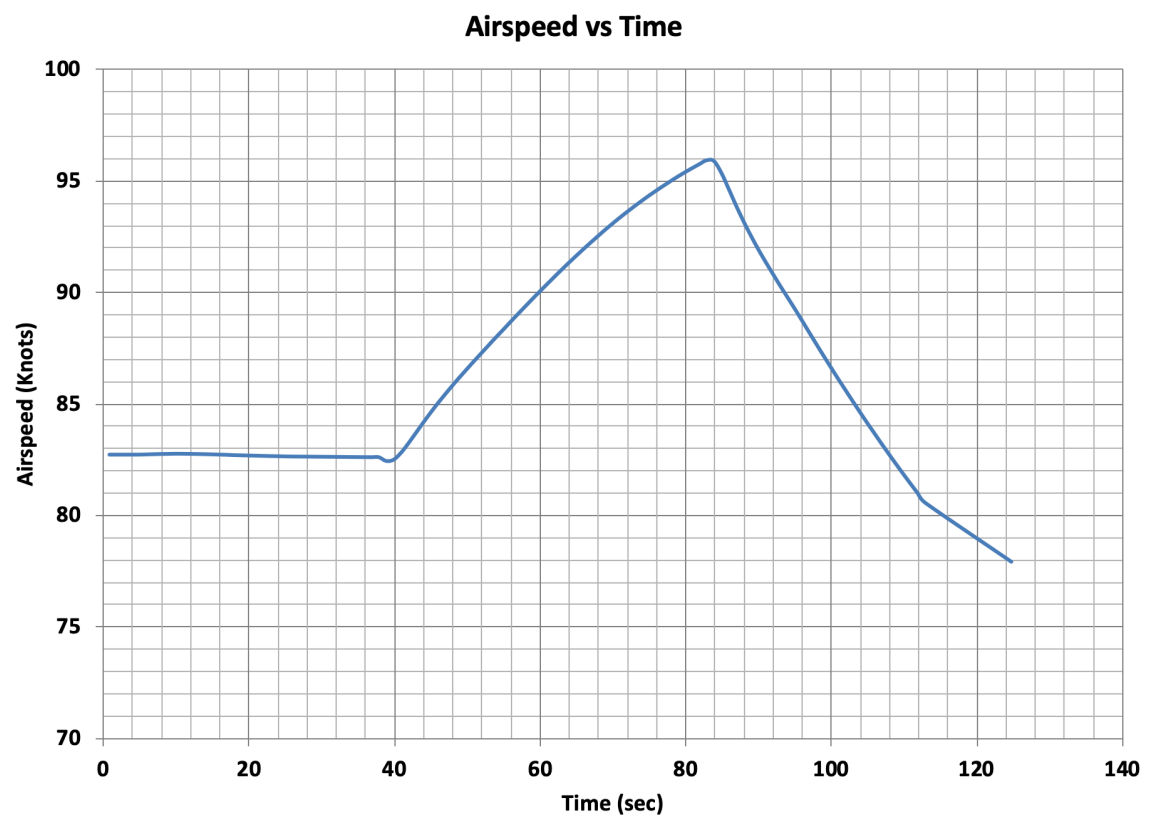

(a)

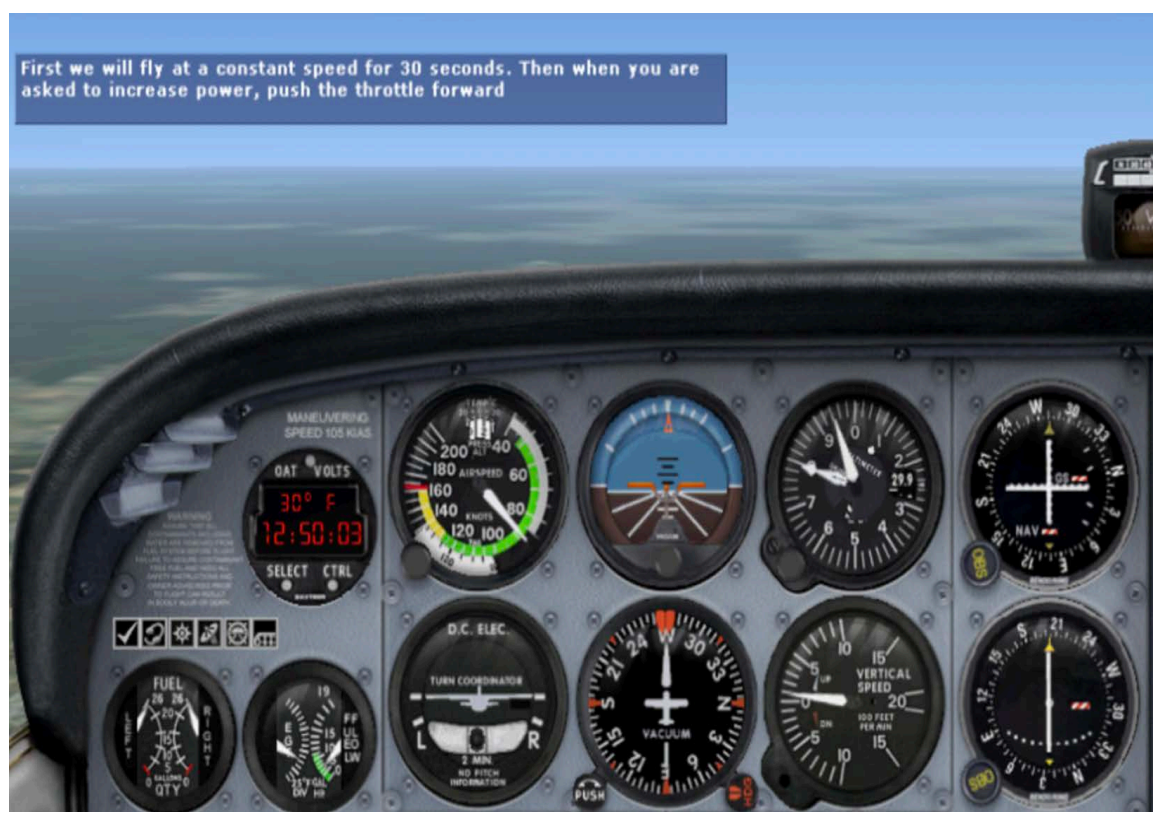

(b)

Figure 2. (a) Real time flight instructions; (b) Plotted flight data.

Development was measured using the Science Teachers Efficacy Beliefs Instrument (STEBI-A) and the Math Teachers Efficacy Beliefs Instrument (MTEBI) developed and validated by [9] for in-service teachers. These instruments have 25 Likert scale items (1-Strongly Disagree (SD), 2-Disagree (D), 3-Neutral (N), 4-Agree (A), 5-Strongly Agree (SA)), and two subscales, the Personal Mathematics/Science Teaching Efficacy (PM/STE) subscale and the Mathematics/Science Teaching Outcome Expectancy (M/STOE) subscale. The instrument has a reported $\alpha=0.91$ for the PMTE scale and an $\alpha=0.76$ for the MTOE subs- 
cale and independence of the two subscales through confirmatory factor analysis. An additional five items were included to determine the teachers' attitudes towards the use of technology in the classroom. The STEBI and MTEBI pre and post professional development were administered to the participant teachers. The post-workshop survey consisted of 21 Likert scale items (1-Strongly disagree (SD), 2-Disagree (D), 3-Neutral (N), 4-Agree (A), 5-Strongly agree (SA)) and 9 open-ended questions. The survey was used to determine the teachers' perceptions about the workshop organization (durations, facilitators), effectiveness of professional development (active learning, reflection, content focus, self-efficacy), pedagogical approach (effectiveness and implementation), content (alignment with standards, design of the learning modules).

\section{Results and Discussion}

The pre-post responses to MTEBI and STEBI were analyzed using two-tailed, paired " $t$ " tests. In general, an increase in the self-efficacy and outcome expectancy was observed from a comparison of the pre-post data (Figure 3). However, statistical significance $(\mathrm{p}<0.05)$ of the pre-post changes could not be established due to the small sample size.

The change between pre-post responses are shown in Figure 4. The negative percentage in both STEBI and MTEBI graphs represent the increased disagreement with the negative questions. Some of these changes are discussed below.

$\mathrm{Q} \# 1$. When a student does better than usual in mathematics, it is often because the teacher exerted a little extra effort.

There was a positive change ( $24 \%$ for science teachers and $12 \%$ for math teachers) that a teacher's effort matters (M/STOE).

$\mathrm{Q} \#$ 7. If students are underachieving in sciencel mathematics, it is most likely due to ineffective sciencel mathematics teaching.

An increase of $41 \%$ was registered in the science teachers' post-response to this statement. This change indicated that mainly the science teachers recognized the impact of effective teaching on learning (M/STOE).

Q\#8. I generally teach sciencel mathematics ineffectively.

The teachers increased their disagreement post-workshop (science teachers, $-13 \%$; math teachers, $-26 \%)$ with the statement (PM/STE).

Q\#9. The inadequacy of a student's science/mathematics background can be overcome by good teaching.

The math teachers' agreement with the statement increased by $10 \%$ in the post-workshop responses (M/STOE).

$\mathrm{Q} \# 14$. The teacher is generally responsible for the achievement of students in science/mathematics.

The math teachers increased their agreement with the statement by $19 \%$ (M/STOE).

Q\#20. Effectiveness in science/mathematics teaching has little influence on the achievement of students with low motivation. 

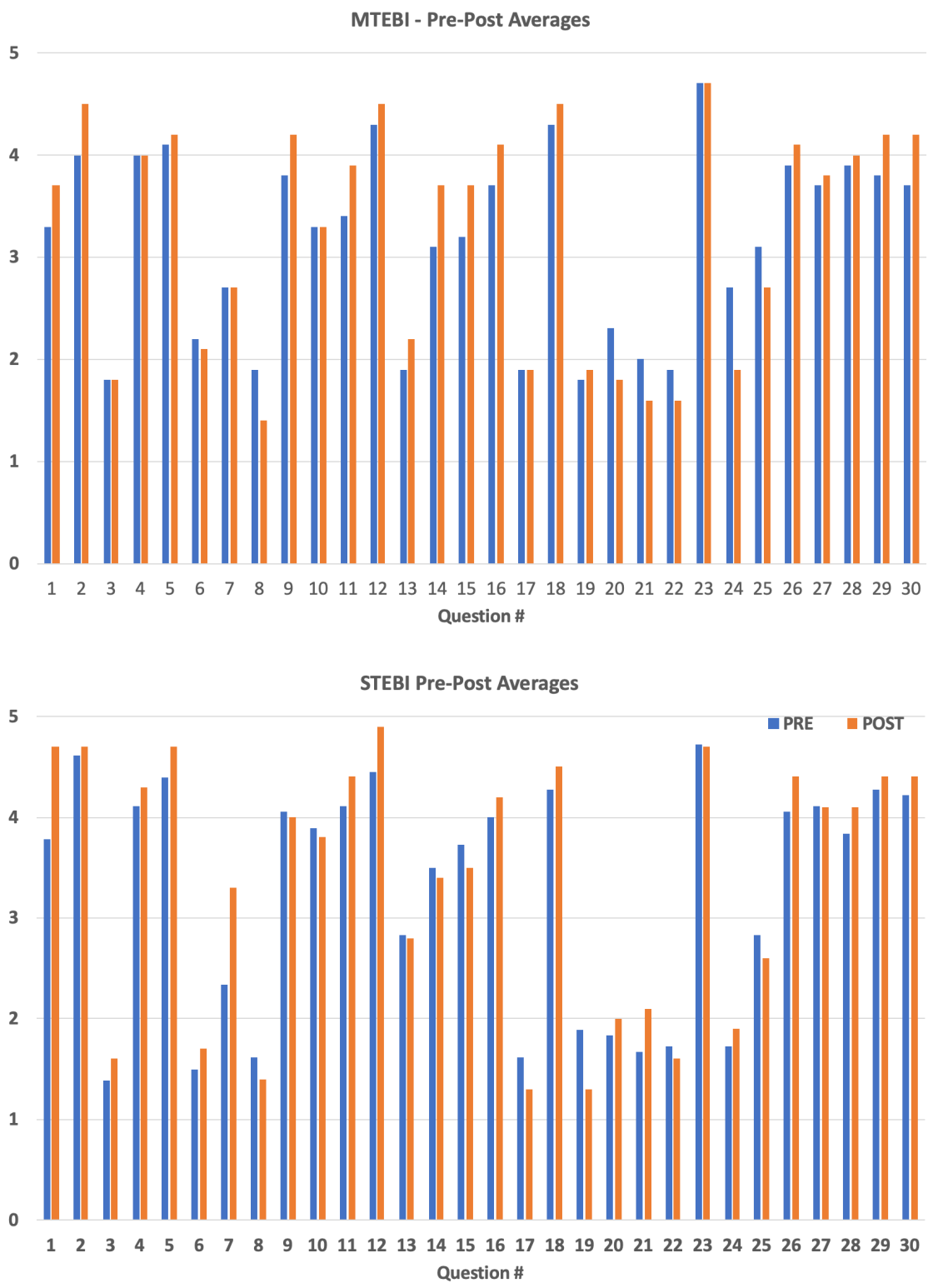

Figure 3. MTEBI and STEBI pre-post average responses.

The mathematics teachers' disagreement with this statement increased by $18 \%$ (M/STOE).

$\mathrm{Q} \# 24$. I do not know what to do to make students interested and like science/mathematics.

The mathematics teachers were feeling more confident post-workshop (30\%) to make students interested in the learning of mathematics while in contrast the science teachers slightly increased in their agreement (10\%) with this statement.

Q\#30. Students evaluate my teaching more positively if I integrate technology in the classroom.

The mathematics teachers increased their agreement (14\%) with the statement that the students will respond positively to teaching with technology as compared to $4 \%$ increase in the science teachers' responses. 


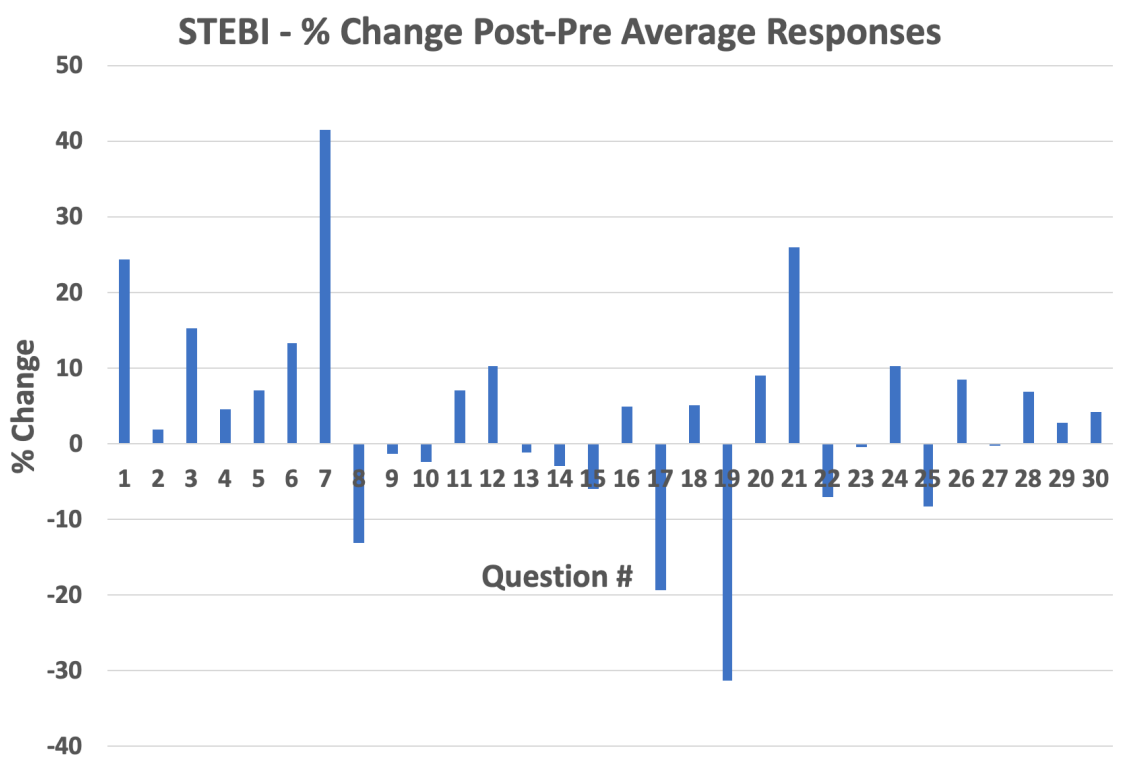

MTEBI - \% Change Post-Pre Average Responses

30

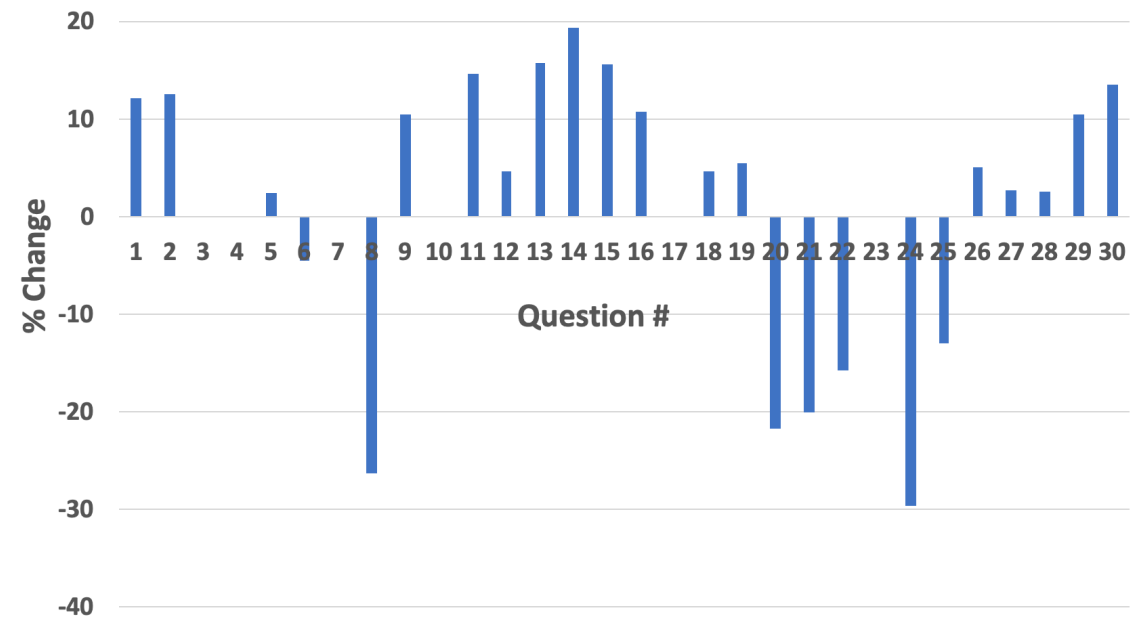

Figure 4. Change in pre-post average responses.

In addition to the M/STEBI surveys analysis, the post-workshop survey responses were analyzed to determine the effectiveness of the professional development workshop, self-efficacy of the participants to use the pedagogical approach, and effectiveness of the pedagogical approach. Figure 5 provides averages of the responses of the participants to the various survey questions grouped into these four categories.

Some typical responses from the teachers to the open-ended questions are given below.

1) What did you like best about the workshop?

- A quite useful amount of reasoning to incorporate more science concepts into my math teaching especially with certain concepts. 


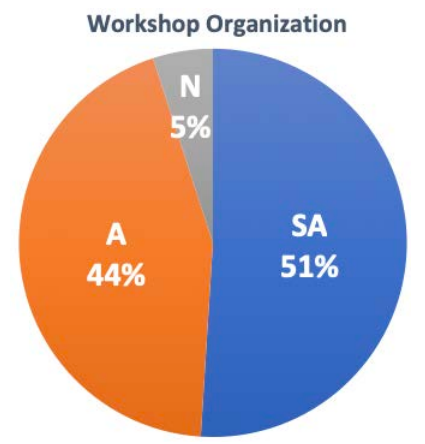

(a)

Effectiveness of Professional Development

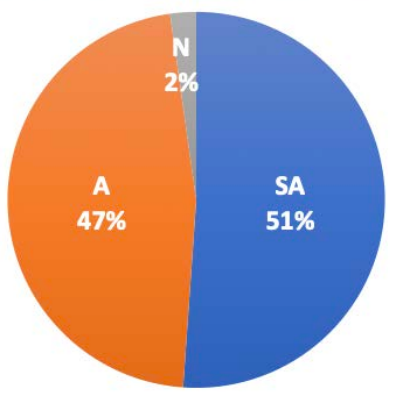

(c)

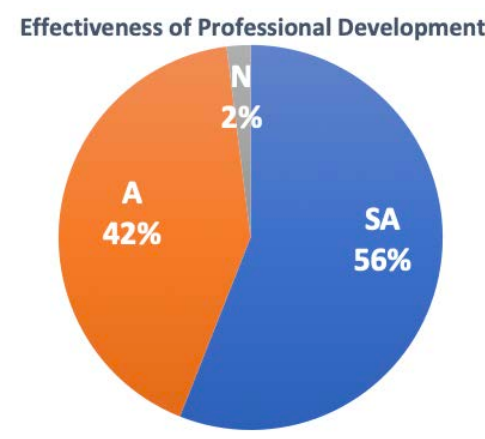

(b)

Self Efficacy of Implementation

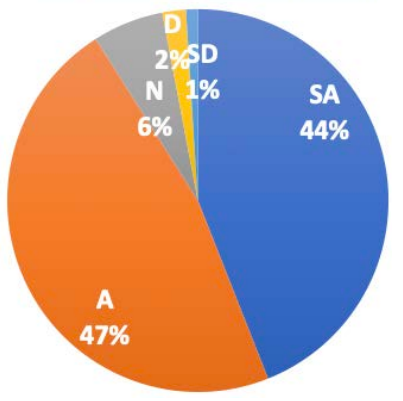

(d)

Figure 5. Responses to post-workshop survey. (a) Organization of the workshop; (b) Effectiveness of the pedagogical approach; (c) Effectiveness of the professional development; (d) Self efficacy of implementation.

- I have gained more knowledge as to using information on scatter plots for comparison of data. Also, how technology simulation can be used to create data to engage students.

- Reinforcement of connecting math concepts to real-life application at all times for student relevance.

- I learned a new and effective way to merge several different subjects into one lesson (Math, Science, and Technology).

- Along with learning about flight simulation, I also learned how to effectively use excel to calculate, and create graphs. I really enjoyed this workshop

- How to apply math and science standards to real world applications

- I really enjoyed the hands-on flight simulator. It was very interesting and engaging as an adult, so I know the students will enjoy.

- Creating the module was helpful in determining the basic concepts then relating them to the real world!

2) What did you like least about the workshop?

The majority of the responses were that they liked all aspects of the workshop. The following are the only suggestions in response to this question:

- Need more flight time

- Could be done in shorter days

- I like the extended lecture presentations the least. I think the "lecture" portions should be kept to a 15-minute maximum time. 


\section{Conclusion and Future Work}

The responses of the participants of the workshop indicated that the professional development was effective. The pedagogical approach presented in the workshop was considered to be potentially effective in engaging students and improving their learning outcomes. The M/STEBI data showed that the workshop increased the math/science teaching efficacy beliefs and teaching outcomes expectancy of the teachers. The post-workshop survey results also indicated that the teachers have high self-efficacy to successfully use the pedagogical approach in their classrooms.

The required hardware and software have been installed in one middle school and it is expected that the teachers will be using it during the spring semester of 2019. Another set of hardware and software will be installed in one additional middle school during the spring semester of 2019 so that the teachers can incorporate the approach in their teaching starting next academic year of 2019-2020. A third professional development workshop will be held in the summer of 2019. Additional teaching modules are being developed to be used by the teachers.

\section{Acknowledgements}

This research was funded by the Innovative Technology Experiences for Teachers and Students (ITEST) program of the National Science Foundation (NSF), Grant\# 1614249.

\section{Conflicts of Interest}

The authors declare no conflicts of interest regarding the publication of this paper.

\section{References}

[1] Pew Research (2017). http://www.pewresearch.org/fact-tank/2017/02/15/u-s-students-internationally-mat h-science/

[2] NEA (2019). https://www.nea.org/assets/docs/18021-Closing_Achve_Gap_backgrndr_7-FINAL. pdf

[3] U.S. Department of Education Office for Civil Rights (2018). https://www2.ed.gov/about/offices/list/ocr/docs/stem-course-taking.pdf

[4] Spires, H.A., Lee, J.K., Turner, K.A. and Johnson, J. (2008) Having Our Say: Middle Grade Student Perspectives on School, Technologies, and Academic Engagement. Journal of Research on Technology in Education, 40, 497-515. https://files.eric.ed.gov/fulltext/EJ826088.pdf https://doi.org/10.1080/15391523.2008.10782518

[5] Department of Education Report (2018). https://www2.ed.gov/about/inits/ed/rural/rural-education-report.pdf

[6] Dowson, P. (2015). https://secure.simmarket.com/pete-dowson-fsuipc4.phtml 
[7] Wideview (2019). https://www.wideview.it/wideview.htm

[8] Darling-Hammond, L., Hyler, M.E. and Gardner, M. (2017) Effective Teacher Professional Development. Learning Policy Institute, Palo Alto.

[9] Riggs, I. and Knochs, L. (1990) Towards the Development of an Elementary Teacher's Science Teaching Efficacy Belief Instrument. Science Education, 74, 625-637. https://doi.org/10.1002/sce.3730740605 